\title{
Undergraduate Students' Perceptions of Virtual Teaching
}

\section{Pinelopi Krystalli}

Aristotle University of Thessaloniki, Thessaliniki, Greece

\section{Abstract}

Following the first Covid-19 cases in Greece, the Ministry of Education decided to close all educational institutions on 10 March 2020. On 12 March, the Chancellor of Aristotle University of Thessaloniki, where the author currently teaches, urged the academic community to create virtual classrooms and begin distance learning. The purpose of this contribution is to investigate undergraduate students' perceptions of virtual classrooms and distance learning. To this end, a qualitative research was conducted, including 50, third year undergraduate students of the Department of French Language and Literature. Students' perceptions, were investigated through a mini-interview. Responses were recorded, transcribed and categorised according to specific criteria. Students compared in-person and distance lessons, referred to the pros and cons of both types of teaching to support their arguments focusing on the content of the lecture or seminar, the type of activities as well as the lecturers' ability to use technology. Finally, in this paper a section of lessons learned from the teacher's point of view are included.

Keywords: virtual teaching, virtual classroom, students' perceptions, distance education

\section{Introduction}

The COVID-19 pandemic caused the most significant disruption to global education systems in history. The impact of this crisis on the quality and conditions of learning has been immense (Unesco, 2020). Educational institutions of all levels which were based only on face-to-face lectures had to swift entirely to online teaching and learning. Subsequently, educators were forced to create virtual classrooms so as to guarantee pedagogical continuity. Following the first Covid-19 cases in Greece, the Ministry of Education and Religions decided to close all educational institutions and University campuses on 10 March 2020. Accordingly, the Aristotle University of Thessaloniki (AUTh) as most universities in Greece resumed the spring semester in the e-learning mode. After the suspension of the university's educational operations, in the framework of the measures to prevent the spread of the coronavirus, the Rectorate Authorities of the AUTh invited, on 12 March, the members of the teaching and research staff to use the available digital tools to create virtual classrooms ensuring an uninterrupted process of education : « Distance courses: to be taken care of by the Presidents of the Departments and the Directors of the Sections, in order to exhaust all the possibilities for the distance learning of the courses. These courses will be considered equivalent to face to face ones and will be counted in the weeks of teaching provided by law. » 1

1 https://www.auth.gr/news/anouncements/27819 
As for the tools and platforms, the distance learning was initially implemented through the use of either the Skype for Business service or the BigBlueButton. The aforementioned services were available to all members of the AUTh -students and teaching staff- through a relevant institutional agreement. Both tools are useful for teaching remote students online and provide real-time sharing of audio, video, slides, chat, and screen. BigBlueButton is available via an MLS system, the elearning.auth.gr, platform that hosts electronic courses of all the AUTh Departments within the undergraduate and postgraduate study cycle. Access is possible only for members of the Aristotle University of Thessaloniki as well as for external users who are certified external collaborators. The Service is supported by the IT-Center and the Library \& Information Center of AUTh. Later during the semester, for the courses with large audiences and especially for exams the ZOOM application was used.

Switching lectures from a face -to- face to a virtual one may be challenging as it demands a great deal of effort. Teachers had to revise not only the structure of their course but also the teaching and the assessment's methods. For this reason, trainings were held by the IT-Center of AUTh which also provided both professors and students with video and tutorials to facilitate the use of the available tools and online systems and platforms. Distance courses, introducing components of systematic synchronous and asynchronous learning, at the Department of French Language and Literature, where the author teaches, began on 16 March. The majority of the teaching staff in this Department initially chose BigBlueButton. However, the author decided to choose Skype for Business to conduct her virtual classes.

The teaching of all the courses up to that moment in the Department was done exclusively face -to-face. However, the students who participated in the research had experience from asynchronous e-learning as many lecturers of the Department use https://elearning.auth.gr/ to upload teaching materials and tasks. During the lockdown this platform also used for different kind of online assessments as well as for the exams. The present study was conducted between May 2020 and June 2020 following two months of synchronous online classes. The evolution of synchronous communication and the generalization of the mobile devices would make it possible to reach the learner everywhere but also immediately and anytime and to combine both the benefits of face-to-face and virtual teaching. However, despite the benefits mentioned in the literature, we found it useful to investigate whether this was a positive experience for our students and what exactly were their perceptions of this type of teaching.

Specifically, in this article we aimed to answer the following key questions:

1. How do undergraduate students perceive their virtual teaching experiences during the COVID-19 Pandemic?

2. What aspects of virtual teaching do the students perceive as beneficial?

3. What are the limitations of virtual teaching and learning in the students' point of view? 


\section{Distance learning and Virtual Classroom}

Distance education, since the middle of the 19th century until today, has made significant steps, based on the means of education offered at all times. Actually, thanks to the integration of digital technologies, distance education fully meets the profile of our students who, as digital natives are flooded every day by network and digital applications. Thanks to this relationship with the digital technologies, distance education or distance learning is also called e-learning or online learning.

The European Commission (2000) defines e-learning as "the use of new multimedia technologies and the Internet, to improve the quality of learning by facilitating access to resources and services, as well as remote exchanges and collaboration".

According to Horton (2006) there many forms of e-learning :

Standalone courses taken by a solo learner.

Learning games and simulations, i.e. learning by performing simulated activities that require exploration and lead to discoveries.

Embedded e-learning, i.e. e-learning included in another system, such as a computer program, a diagnostic procedure, or online Help.

Blended learning i.e. using of various forms of learning to accomplish a single goal. Mobile learning.

Knowledge management which includes broad uses of e-learning, online documents, and conventional media.

Virtual-classroom courses. Online classes structured much like a classroom course. Virtual classroom courses may or may not include synchronous online meetings.

Consequently, e-learning refers to a set of educational environments which make it possible to solve the problem of the spatiotemporal distance, thanks to the use of synchronous and asynchronous modes of communication supported by web tools which are integrated into educational platforms. Additionally, these tools offer the possibility of promoting social interactions between the different actors in these environments (Jézégou, 2010).

A virtual classroom, as Horton (2006) argues, is a special web application that allows users to connect to a common environment using collaboration and communication tools combining image, sound, text, presentations, and various other tools.

For Yang \& Liu (2007) the virtual classroom is a modern online learning environment, which can not only be used to deliver educational materials, but also provide an interactive environment for learners.

Virtual classes are the only way to create a bridge between face-to-face and distance learning. When used wisely, virtual classrooms make it possible not to lose the advantages of the teacher-learner relationship.

Diemer (2012) mentions three important advantages of virtual classes: a. they make it possible to visualize the teacher-learner relationship. Maintaining the teacher's posture 
continues to provide tangible benchmarks to learners (this is a characteristic of the webcam); b. they are presented as self-learning and self-training modules (synchronous and asynchronous classes); c. they register learning over time (training is a process in which the learner evolves at his own pace).

The International Baccalaureate Organization (2020) argues that for an effective virtual course that ensures equal opportunities among learners, learners should have access to the following resources:

Access to devices, including mobile devices, appropriate for online learning.

Internet access and adequate bandwidth as poor bandwidth can make many synchronous activities very difficult.

Effective, immediate and valuable feedback through quizzes and intelligent tutors as well as direct comments or discussion from peers and teachers.

Opportunities for independent learning through learning activities and discussions that capture students' engagement.

Meaningful screen time and conferencing.

According to Yang and Liu (2007) a successful and efficient virtual classroom depends on selfpaced learning, interaction between teachers and learners, contextual learning and discussion and, live, spontaneous learning resources.

Researchers also argue that the teacher's ability to help students become autonomous and to enhance and maintain motivation for learning are important factors that influence distance virtual teaching (Hurd, 2006, Lo Presti, 2020).

Several arguments are listed in favor of virtual teaching such as accessibility, affordability, flexibility, learning pedagogy and life-long learning (Dhawan, 2020).

According to Horton (2006) in a virtual class the teacher has the possibility to adapt learning to learners and adjust content immediately in response to feedback from learners. Learning can be flexible and active because virtual classes combine lecture, visual and oral interaction, individual and team activities. In addition, he argues that the virtual class provides the discipline some learners need, as face-to-face contact with the instructor and peer pressure combine to keep learners on schedule.

\section{Methodology}

\subsection{Research Design}

In order to collect in-depth information about students' views in virtual teaching, discussion and individual semi-structured interviews were conducted to collect the data. The interviews took place via Skype for business because of the confinement after a three-month experience in virtual classrooms. The individual interview provided students with the occasion to describe their experience in their own words. Interviews lasted approximately 3 minutes and were recorded, transcribed and categorized according to specific criteria. 


\subsection{Participants of the study}

A total of 50 third undergraduate students participated in the research. The participants, were students in the Department of French and Literature, of Aristotle University that attended the French Language course: Oral Speech Skills Development during the spring semester 2020. These students had not previously participated in a synchronous distance education experience. The researcher, as a teacher of this course, observed changes in students' behaviors compared to in-person seminars and subsequently decided to explore students' opinions about the virtual classroom. During the semester, these students attended an average of 8 distance synchronous learning courses using Skype for busines or BibBlue Buttom. During the mini-interview the participants were asked to answer the following questions:

What is your opinion about virtual classrooms? Do you appreciate them or do you prefer the face-to-face courses?

Could you give specific examples from your personal experience highlighting the pros and cons of virtual teaching?

\subsection{Data Collection and Analysis}

The data analysis was done in several phases. During the first phase, the recorded interviews were transcribed. A series of reviews and analysis followed. The first review aimed to remove elements that were not directly related to the research topic. In other words, this was a first reduction of the data. In the second phase, answers were recorded including the answers that were in favor of virtual classroom and distance learning, the answers that were against and those that considered both types of teaching to be equally effective. In the next phase, following in-depth analysis, the answers were grouped into either one of two main categories: a) aspects of virtual teaching that students perceive as beneficial and b) the virtual teaching and learning limitations.

\subsection{Findings}

Findings from the analysis of qualitative data are presented in this section.

3.4.1 Students' overall perceptions of their virtual classrooms experienceAlthough the participants think virtual teaching offer new ways of learning and was the best solution during the confinement as to not miss the semester, the majority of the participants answered they prefer face-to-face teaching (38 out of 50). Seven participants argued that virtual teaching can be as effective as the face-to face one if there is interaction and if the teacher is comfortable handling the tools offered by the platform. Virtual teaching generated positive impacts for only five participants. Examples of students' comments are found below:

- Virtual classrooms are somewhat effective, but I do not think they can substitute the traditional face-to-face course.

- Distance learning even when synchronous is incomplete and ineffective.

-Some teachers are very familiar with the technology. This resulted in some virtual classes to be highly interactive and motivating as they required the active engagement of students.

-Virtual classrooms gave me the opportunity to learn in different ways.

- I prefer the virtual classroom because I feel more comfortable. In contrast to the traditional classroom, I do not hesitate to ask things in front of everyone. 
- Virtual classrooms were a very good experience. I think we worked as well as in the traditional classroom.

\subsubsection{Perceived Benefits of virtual teaching}

Even though, the majority of students prefer face-to-face courses, they believe that the virtual classroom has several significant benefits. First of all, the participants, especially those who had a positive attitude towards virtual teaching, appreciated the design of the virtual environment and flexibility of the collaboration tools. Participants argued that collaborative tools enhanced their interactions with peers and teachers and provided opportunities for discussion and effective collaboration. Moreover, participants claimed that collaborative tools such as the chat and breakout rooms helped them overcome the shyness or the fear of asking questions. They were now more eager to make comments or give answers expressing themselves freely. Examples of students' comments are found below:

I never contribute in the discussion in face-to-face classes because I am shy. In the virtual classroom however, I managed to make comments in the chatbox without feeling embarrassed.

Breakout rooms gave me the opportunity to interact with my teammates and motivated me to work harder.

-I certainly prefer to interact in the virtual space. I used the chatbox to communicate with my classmates and to make queries to the teacher.

When I make a face-to-face presentation in class, I get stressed, however when using the screen and the microphone I perform better.

I had never taken distance courses before. Now, that I am used to the tools, I prefer virtual teaching.

Participants also argued that in some virtual courses, especially in language and translation courses, teachers used creative online tasks and activities that increased engagement, motivation and participation. Furthermore, they argued that the courses where teachers flipped their classrooms presenting content asynchronously through videos and online activities, resulting in spending more time collaborating with one another during the virtual classroom and gave time for discussions. Examples of such comments are found below:

In some language courses teachers focused on sharing knowledge and information which resulted in the course being more engaging and interesting.

In some courses we had to complete tasks and activities asynchronously. Thus, the teacher had more time to group potential problems and give explanations during the virtual classroom.

When the teacher flipped the classroom, I could study the theory before and ask questions in the synchronous teaching.

Other benefits mentioned by the majority of participants, were that, by selecting the study location, they saved time and money since the need for expensive and time-consuming traveling was eliminated. They also pointed out that the stress caused by moving to and from university has been reduced. Comments below:

My family's finances have been worsened during the pandemic. Saving money from travel and other living expenses helped my family. 
Before the pandemic, I spent an hour every day on the bus to go to University. With virtual classrooms, I spent this time studying.

I used to have a part-time job to cover my living expenses. During the pandemic, I lost my job but it did not bother me because I had no travel and accommodation expenses.

Finally, more than half of the participants, even those who were unfavorable, argued that distance learning helped them develop time management skills, increase self-confidence and become autonomous learners. Examples of such comments are found below:

I think that distance learning, during the pandemic, helped me improve my organizational skills. It was a challenge for to do homework assignments in time.

In the past three months since the covid-19 outbreak, I became more responsible and learned how to plan my day more effectively. I have no reason not to do. I was home all the day.

The immediate feedback from the online quizzes and activities helped me to improve my grades and my linguistic skills.

The following table summarizes the benefits that positively affected students' opinions in relation to the factors related to virtual teaching.

Table1.Perceived benefits of virtual teaching

\begin{tabular}{|c|c|}
\hline Factors & Benefits \\
\hline $\begin{array}{c}\text { Flexibility of the communication and } \\
\text { collaboration tools }\end{array}$ & $\begin{array}{c}\text { Interaction, collaboration, active } \\
\text { participation }\end{array}$ \\
\hline $\begin{array}{c}\text { Content of the course, Method adopted } \\
\text { by the teachers }\end{array}$ & $\begin{array}{c}\text { Interaction, engagement and motivation } \\
\text { Choosing location }\end{array}$ \\
\hline Distance learning & $\begin{array}{c}\text { Saving time and money } \\
\text { Less stress }\end{array}$ \\
\hline & $\begin{array}{c}\text { Time management skills, self-confidence } \\
\text { and autonomy }\end{array}$ \\
\hline
\end{tabular}

\subsubsection{Perceived limitations of virtual teaching}

Several limitations derive from the interviews and the discussion. These can be grouped as follows: technical problems, the lack of technological literacy of both students and teachers, as well as the lack of efficient teaching methods. the lack of face-to-face communication.

A primary negative element of virtual teaching was that the majority of participants reported problems with internet connection and therefore poor sound and screen image quality, lack of personal equipment (camera, headphones) and network speed and bandwidth at home. Examples of students' comments are found below:

-In the area where I live, we have poor internet speed. This was aggravated especially during the confinement where the whole family was using the internet.

- Without headphones, the noise from the street and the bad connection prevented me from listening to the teacher.

- During the first month, the platforms were overloaded and we had to keep the camera off, so I had no eye contact with either the teacher or my classmates. Because of that, I was completely demotivated. 
- The frequency of disconnections, distracted me significantly.

- With the camera off, without eye contact and poor volume levels, I felt alone at times.

Moreover, participants highlighted that inadequate pedagogical or ICT skills of the online lecturers demotivated them. According to students, for some lecturers it was very difficult to adjust their methods to the virtual environment and to use effectively the integrated collaborative tools. That affected negatively their engagement and motivation.

Furthermore, a small number of participants, pointed out that they were unfamiliar with the new technologies. Hence, it was very difficult for them to use the tools especially when they were presenting something to the class themselves. Examples of such comments are found below:

-I use the technology for Facebook or insta but during the virtual class I had many difficulties.

- Watching a power point for three hours and listening to the lecturer speak without giving an example on the board was really boring!

- If the virtual class is a continuous monologue, I certainly prefer the traditional one.

- If I had the choice I would never be enrolled on distance literature courses. The lack of interaction in some cases demotivated me.

Finally, participants argued that even a well-designed virtual classroom cannot substitute completely the face -to -face lectures. They also argued that the large number of hours spent in front of the screen, resulted to health issues. Examples of such comments are found below:

-Even though we had no choice and we had to complete the semester virtually, I missed the communication with my classmates before and after classes.

- The lack of in-person teaching, resulted in lack of communication or interaction before and after lectures. Therefore, I believe that distance education has a negative impact on social relations.

- the large number of hours spent in front of the computer every day, increased my myopia and led to back pains.

Table2. Perceived limitations of virtual teaching

\begin{tabular}{|c|c|}
\hline Factors & Benefits \\
\hline $\begin{array}{c}\text { Technical problems } \\
\text { Poor network speed and bandwidth }\end{array}$ & Distraction and lack of motivation \\
\hline $\begin{array}{c}\text { Inadequate teaching materials and } \\
\text { methods } \\
\text { ICT skills }\end{array}$ & $\begin{array}{c}\text { Lack of engagement and motivation } \\
\text { Distance }\end{array}$ \\
\hline $\begin{array}{c}\text { Limited interaction and communication } \\
\text { with peers and lecturer }\end{array}$ \\
\hline $\begin{array}{c}\text { Duration of virtual teaching and } \\
\text { learning }\end{array}$ & Health problems \\
\hline
\end{tabular}




\section{Discussion and Conclusion}

This article aimed to examine students' perceptions of virtual teaching after their experience during the pandemic. As it emerged from the interviews and the discussions the majority of the students who participated in the research were not in favor of virtual classrooms. According to the findings, the most important factors that significantly influence students' perceptions of the virtual classroom are as follows: the use of the integrated communication and collaboration tools, the content of the course and the pedagogical methods used by the lecturers, the ICT skills of the users, lecturers as students as well, technical problems and lack of equipment and of course the distance. Students argued that some modules, such as literature, are not appropriate for the synchronous distance education. In fact, the course design and structure can either enhance student's engagement and motivation or demotivate them ( Hartnett, St. George, \& Dron, 2011). The findings showed that in some course's long duration and the lack of interaction affect the students negatively. Students complained about technical problems, such as slow and unreliable internet connectivity. Students also pointed out that they missed in-person tutoring and human interaction with their teachers and peers.

At AUTh undergraduate courses are traditionally take place in-person, so the virtual classroom was not a choice but a necessity imposed by the pandemic. Consequently, some lecturers were not prepared to face the challenges of the virtual teaching. Furthermore, there was no time for training and familiarization with the platforms and tools and the updating of teaching methods and materials. The lack of ICT skills of both teachers and students negatively affected the degree of students' satisfaction of virtual teaching. Consequently, to conduct effective virtual classrooms the teaching staff should be trained. Furthermore, the students must be helped to develop their skills in digital literacy.

To conclude, the author believes that the virtual classroom can be as effective as the traditional one as long as it is designed properly and the teaching materials are suitable and adequate for this type of teaching. Thus, we can enhance students' motivation and engagement.

Therefore, further research might explore the correlation between students' and lecturers' perceptions of virtual teaching. Research also could focus on criteria for motivational and engaging learning activities in virtual classrooms as well as on the effective use of the collaborative tools. In fact, it would be helpful to look for design criteria in a virtual classroom that can increase students' engagement and enhance students' motivation.

\section{References}

[1] Bonk, C., Wisher, R., \& Lee, J. (2004). Moderating Learner-Centered E-Learning: Problems and Solutions, Benefits and Implications in Tim S. Roberts Online Collaborative Learning: Theory and Practice, European Commission,

[2] Dhawan, S. (2020) Online Learning: A Panacea in the Time of COVID-19 Crisis, Journal of Educational Technology Systems, 1-18.

[3] DIEMER, A. (2012) Formation de formateurs dans le milieu de l'entreprise, des collectivités et des services : Comment concilier projet pédagogique et offre de formation à distance dans l'espace francophone?, IN T. Karsenti, R. P Garry, A., Benziane, B.B., Ngoy-Fiama \& F. Baudot (Eds), La formation de formateurs et d'enseignants à l'ère du numérique : stratégies politiques et accompagnement pédagogique, du présentiel à l'enseignement à distance. Montréal : Réseau international francophone des établissements de formation de formateurs (RIFEFF) / Agence universitaire de la Francophonie (AUF). 
[4] Hartnett, M., St. George, A., \& Dron, J. (2011). Examining motivation in online distance learning environments: Complex, multifaceted and situation-dependent. The International Review of Research in Open and Distributed Learning, 12(6), 20-38. https://doi.org/10.19173/irrodl.v12i6.1030

[5] Horton, K.W. (2006). E-Learning by Design. San Francisco, CA: Pfeiffer.

[6] Hurd, S. (2006). Towards a better understanding of the dynamic role of the distance language learner: learner perceptions of personality, motivation, roles, and approaches. Distance Education, 27(3), pp. 303-329.

[7] International Baccalaureate Organization (2020), Online learning, teaching and education continuity planning for schools, [Online] Available: https://www.ibo.org/globalassets/newsassets/coronavirus/online-learning-continuity-planning-en.pdf.

[8] Jézégou, A. (2010). Créer de la présence à distance en e-learning: Cadre théorique, définition, et dimensions clés. Distances et savoirs, vol. 8(2), 257-274.

[9] Lo Presti, M. V. (2020). Second Language Distance Learning: The Issue of Language Certification in the Time of COVID-19. European Journal of Education, [S.I.]v. 3, n. 2, pp. 89-102.

[10] Yang, Z., \& Liu, Q. (2007). Research and development of web-based virtual on-line classroom. Computers \& Education, 48, 171-184. 